\title{
INFLUENCE OF POLYMORPHIC TRANSFORMATIONS ON THE POROSITY OF PLASMA- SPRAYED PRODUCTS FROM PURE ALUMINUM OXIDE
}

\author{
Igor BELYAEV ${ }^{1}$, Alexey STEPNOV ${ }^{2}$, Viacheslav BAZHENOV ${ }^{3}$, Artem PAVLOV $^{4}$, \\ Andrei KIREEV ${ }^{1}$ \\ 1 Vladimir State University named after A.G. and N.G. Stoletovs, Vladimir, Russian Federation, \\ belyaev-iv54@yandex.ru \\ ${ }^{2}$ Research and Production Enterprise "Center for Plasma Spraying" LLC, Vladimir, Russian Federation, \\ stepnov86@mail.ru \\ ${ }^{3}$ National University of Science and Technology "MISiS", Casting Department, Moscow, Russian Federation, \\ v.e.bagenov@gmail.com \\ 4 "Coating Technologies", Vladimir, Russian Federation, \\ pavlovaa@mail.ru
}

https://doi.org/10.37904/metal.2019.728

\begin{abstract}
In the present work, the influence of polymorphic transformations on the porosity of plasma sprayed products produced from pure aluminum oxide was investigated. Scanning electron microscopy, quantitative X-ray diffraction analysis, and X-ray computer tomography are used to quantify the porosity. It was established that the plasma sprayed products is a mixture of $\alpha, \gamma$ and $\delta$ aluminum oxides with different densities. When heating, these phase modifications undergo the polymorphic transformations which are accompanied by change in the volume. Opposite variations in the volume of the modifications can lead to both decrease and increase in porosity of material as the temperature of heat treatment increases. It was shown that the non-monotonic behavior of temperature dependence of the porosity is shown to be steadily repeated; this is related to the occurrence of polymorphic transformations. This allows us to change purposefully the porosity of plasma sprayed pure aluminum-oxide products by heat treatments.
\end{abstract}

Keywords: Plasma sprayed products, aluminum oxide, heat treatment, polymorphic transformations, porosity

\section{INTRODUCTION}

The plasma-sprayed products produced from the pure aluminum oxide are characterized by the accuracy of geometry, fire resistance, and chemical inertness with many substances. The material of these products does not contaminate substances being in contact with it by foreign impurities. In this regard, plasma-sprayed products from pure aluminum oxide are widely used in practice [1-3].

Porosity is the special feature of the plasma-sprayed products material. The porosity gives new features to this material. A change in the porosity affects the physical properties (gas permeability, thermal conductivity) of this material $[4,5]$. The possibility of porosity control allows to control the physical properties of the plasmasprayed products material. Regularities of plasma-sprayed products porosity change that made of the pure aluminum oxide are poorly understood. In [6-9], data on the effect of manufacturing factors of plasma spraying on the porosity of Al2O3 coatings are presented. In our paper, we investigate the effect of polymorphic transformations on the porosity of plasma-sprayed products made from the pure aluminum oxide.

\section{MATERIALS AND METHODS}

As the raw material for the plasma spraying we used crushed white electrocorundum powder with an average particle size of $32 \mu \mathrm{m}$. The material contained the following impurities (\% wt): Pb-0.24; Cu-0.15; Zn-0.05; Fe$0.3 ; \mathrm{Zr}-0.24$. Samples for the study were prepared by plasma spraying of material on a steel substrate. 
The plasma spraying was realized using a UPN-350 (Russia) installation. Compressed air was used as a plasma-forming gas. Before spraying, the substrate was at room temperature. The conditions of plasma spraying were always unchanged; the process was realized at a current of plasmatron arc of 125-130 A, a voltage of 200-210 V, a pressure of plasma forming gas (air) of $0.5 \mathrm{MPa}$, a powder consumption of 5-6 kg/hour, a spraying distance of $200 \mathrm{~mm}$, and a speed of the plasmatron motion relative to the sprayed surface of 20 $\mathrm{mm} / \mathrm{s}$.

The investigated samples were heat treated in a LH 30/13 (Nabertherm, Germany) resistance furnace. Quantitative phase analysis was performed using a D8 Advance X-ray diffractometer (Bruker AXS, Germany) in CoKa radiation. Diffraction patterns was quantified using TOPAS software.

The porosity was measured by X-ray computed tomography using a "NANOMEX" installation (Germany) and Volume Graphics VG MAX 3.2 software to process the data obtained. The pores layout and distribution were studied by scanning electron microscopy using a Tescan Vega 3 SBH scanning electron microscope (Czech Republic) equipped with an Oxford energy dispersive X-ray spectroscopy (EDS) system (UK); the studies were performed on metallographic sections and fractures of samples.

\section{RESULTS AND DISCUSSION}

It is known that the aluminum oxide is characterized by complex polymorphism and has a number of phase modifications [10-12]. These modifications differ from each other in the crystal symmetry and lattice parameters and in the density as well. The literature data available are given in Table 1.

Table 1 Characteristics of some structural modifications of aluminium oxide [4,5,10-14].

\begin{tabular}{|c|c|c|c|}
\hline Modification & Crystal lattice & Lattice parameters, $\mathbf{n m}$ & ${\text { Density, } \mathbf{g} / \mathbf{c m}^{\mathbf{3}}}^{\alpha-\mathrm{Al}_{2} \mathrm{O}_{3}}$ \\
\hline $\mathrm{\gamma}-\mathrm{Al}_{2} \mathrm{O}_{3}$ & Hexagonal & $\begin{array}{c}\mathrm{a}=0.4754 ; \mathrm{c}=0.1299 ; \\
\mathrm{c} / \mathrm{a}=2.73\end{array}$ & $3.99-4.0$ \\
\hline$\delta-\mathrm{Al}_{2} \mathrm{O}_{3}$ & Cubic & $\mathrm{a}=0.790$ & $3.6-3.65$ \\
\hline & Hexagonal & $\begin{array}{c}\mathrm{a}=0.7937 ; \mathrm{b}=1.59 ; \\
\mathrm{c}=1.1679 ; \mathrm{c} / \mathrm{a}=1.47\end{array}$ & 2.4 \\
\hline
\end{tabular}

It can be seen form the Table that $\alpha, y$ and $\delta$ aluminum oxide modifications can differ in the density by more than 1.5 times. This means that the transformation from one to another modification will be accompanied by a significant change in the volume.

The most common modification of aluminum oxide is the $y$-modification - alumina. In nature, alumina usually is present in the form of alumina hydrates. When heating, alumina hydrates are successively transformed into other intermediate modifications of aluminum oxide and, ultimately, turn into its single stable form - corundum (a-modification of aluminum oxide). The sequence of polymorphic transformations of natural alumina hydrate $\mathrm{Y}-\mathrm{Al}_{2} \mathrm{O}_{3} \times 3 \mathrm{H}_{2} \mathrm{O}$ (hydrargillite) to corundum with increasing temperature is shown in Figure 1 (a). It also shows the temperature of polymorphic transformations and temperature ranges of the stability of intermediate modifications of aluminum oxide.

The plasma spraying was realized using a modification of aluminum oxide (corundum). Passing through the plasma, corundum particles are partially or completely melted. After solidification on a metal substrate (mandrel), the phase composition of the aluminum oxide changes. Data on the phase modifications of aluminum oxide formed during plasma spraying and on the sequence of their polymorphic transformations with increasing temperature are available in [10-12]. These data are shown in Figure 1 (b).

It is obvious from Figure 1 that the set of phase modifications formed in the case (a) differ from those formed in the case (b). Therefore, upon heating, the volume changes of products made from the natural alumina will 
differ from the volume changes of plasma-sprayed products. In accordance with volume changes, the porosity of these products also should differ.

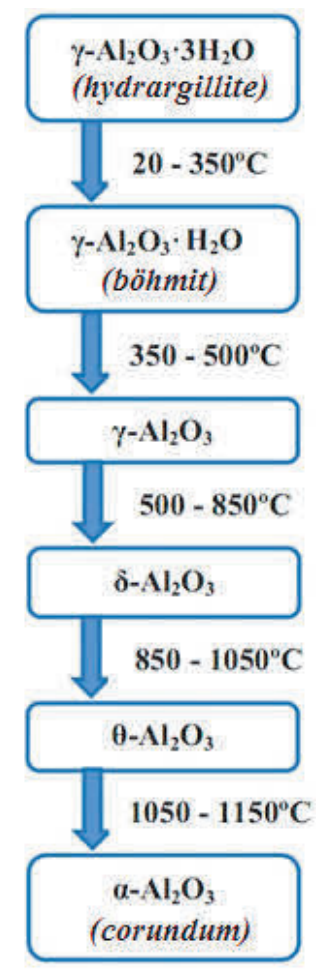

(a)

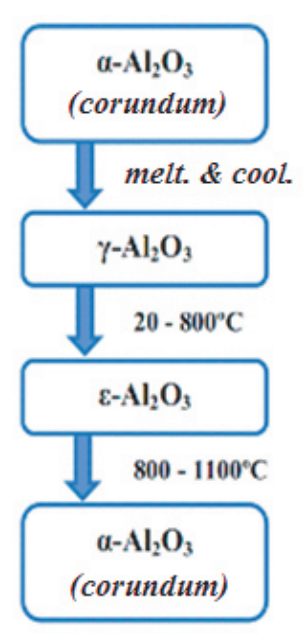

(b)

Figure 1 The sequence of polymorphic transformations of natural hydrates of aluminum oxide (a) and modifications of aluminum oxide (b) formed during plasma spraying with increasing temperature [10-12].

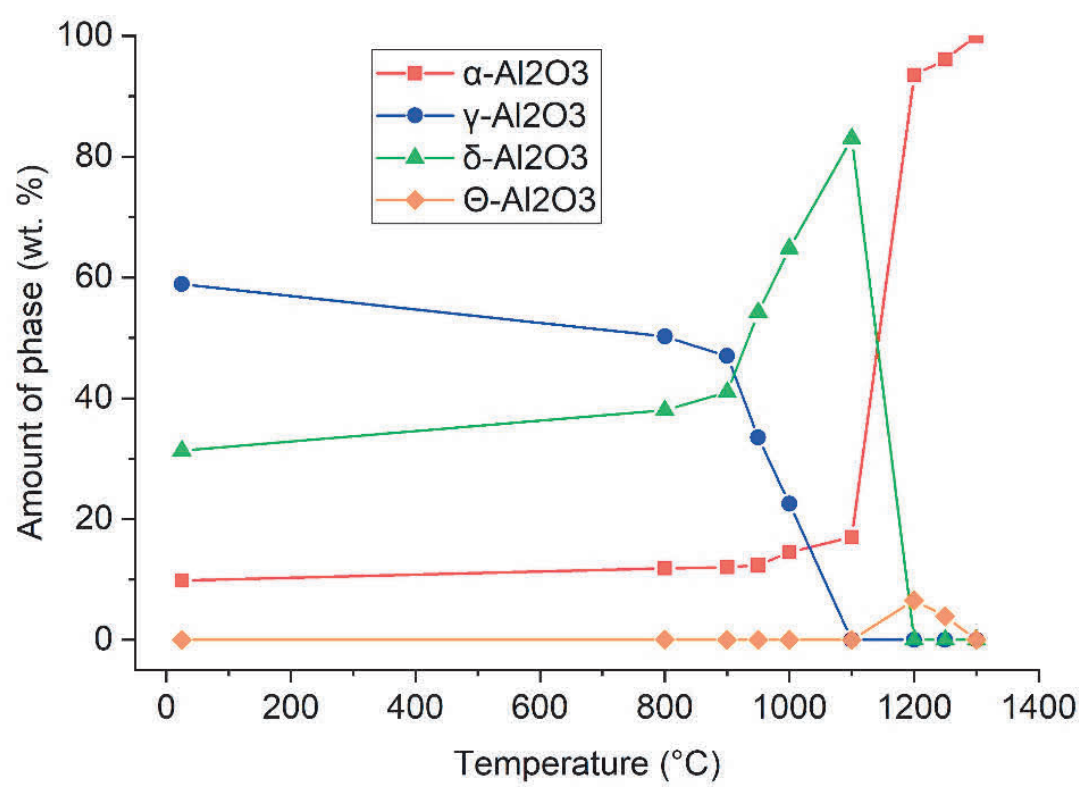

(a)

Figure 2/1 Variations of the phase composition (a) and porosity (b) of the material of plasma- sprayed aluminum-oxide products during heat treatment in accordance with regimes 1-8. 


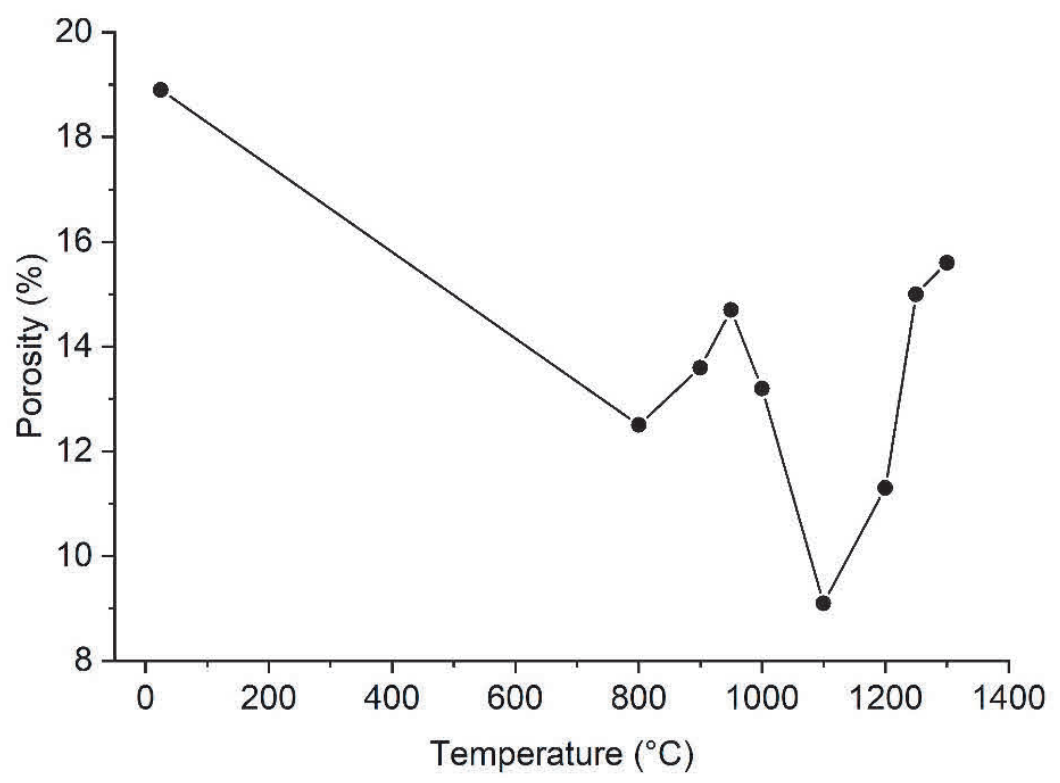

(b)

Figure 2/2 Variations of the phase composition (a) and porosity (b) of the material of plasma- sprayed aluminum-oxide products during heat treatment in accordance with regimes 1-8.

In order to study variations in the porosity during heating of plasma-sprayed products, pure aluminum oxide samples $100 \times 100 \times 2 \mathrm{~mm}$ in size were prepared. Some of the samples were heat treated under the following conditions: heating up to $800{ }^{\circ} \mathrm{C}$ (regime 1), $900^{\circ} \mathrm{C}$ (regime 2), $950{ }^{\circ} \mathrm{C}$ (regime 3), $1000{ }^{\circ} \mathrm{C}$ (regime 4), 1100 ${ }^{\circ} \mathrm{C}$ (regime 5), $1200{ }^{\circ} \mathrm{C}$ (regime 6), $1250{ }^{\circ} \mathrm{C}$ (regime 7), $1300{ }^{\circ} \mathrm{C}$ (regime 8), and subsequent 1-h holding at each temperature. The porosity and phase composition were studied on samples. The analogous studies were carried out on samples that were not heat treated. The obtained results are shown in Figure 2.

It can be seen from Figure 2 that the phase composition of the sample that was not heat treated is a mixture of $\alpha, y$ and $\delta$-modifications of aluminum oxide. The main volume of this mixture corresponds to the $\mathrm{y}^{-\mathrm{Al}_{2} \mathrm{O}_{3}}$ modification. During heat treatments, the amount of $\mathrm{Y}-\mathrm{Al}_{2} \mathrm{O}_{3}$ continuously decreases, and, on the contrary, the amounts of $\alpha-\mathrm{Al}_{2} \mathrm{O}_{3}$ and $\delta-\mathrm{Al}_{2} \mathrm{O}_{3}$, continuously increase. Beginning from $900{ }^{\circ} \mathrm{C}$, the $\mathrm{Y}-\mathrm{Al}_{2} \mathrm{O}_{3}$ content reduction rate and $\delta-\mathrm{Al}_{2} \mathrm{O}_{3}$ content increase rate are become sharply, whereas the increase rate of the $\alpha-\mathrm{Al}_{2} \mathrm{O}_{3}$ content varies slightly. At $1100{ }^{\circ} \mathrm{C}$, the amount of $\delta-\mathrm{Al}_{2} \mathrm{O}_{3}$ reaches a maximum value (about 83 wt. \%), and the $\mathrm{y}^{-\mathrm{Al}_{2} \mathrm{O}_{3}}$ content becomes zero. As the heat treatment temperature increases, the $\alpha-\mathrm{Al}_{2} \mathrm{O}_{3}$ content increase rate of and decrease rate of the $\delta-\mathrm{Al}_{2} \mathrm{O}_{3}$ content abruptly change. At a heat treatment temperature of $1200{ }^{\circ} \mathrm{C}$ (regime 6), the $\delta-\mathrm{Al}_{2} \mathrm{O}_{3}$ modification is completely transformed into $\alpha-\mathrm{Al}_{2} \mathrm{O}_{3}$. In a temperature range of $1100-1300{ }^{\circ} \mathrm{C}$, the $\theta-\mathrm{Al}_{2} \mathrm{O}_{3}$ modification exists. After $1-\mathrm{h}$ holding at a $1300{ }^{\circ} \mathrm{C}$ (regime 8), the entire material of the plasma-sprayed product is $\alpha-\mathrm{Al}_{2} \mathrm{O}_{3}$ (corundum). The $\varepsilon-\mathrm{Al}_{2} \mathrm{O}_{3}$ modification was not found in this work.

It is also seen from Figure $\mathbf{2}$ that the temperature dependence of porosity is non-monotonic. When comparing the dependences "phase composition vs temperature" and "porosity vs temperature" it is easy to see clear correlation between the porosity of plasma-sprayed samples and the polymorphic transformations occurred in the material of these samples with increasing heat treatment temperature. The polymorphic transformation leads to a decrease in the porosity, when the transformation is accompanied by an increase in the volume (for example, when $\mathrm{y}-\mathrm{Al}_{2} \mathrm{O}_{3}$ transforms into $\delta-\mathrm{Al}_{2} \mathrm{O}_{3}$ ) and, on the contrary, a polymorphic transformation leads to an increase in the porosity, when the transformation is accompanied by a decrease in the volume (for example, when $\mathrm{y}-\mathrm{Al}_{2} \mathrm{O}_{3}$ and $\delta-\mathrm{Al}_{2} \mathrm{O}_{3}$ transform into $\alpha-\mathrm{Al}_{2} \mathrm{O}_{3}$ ). The increase and decrease in the contents of various modifications of $\mathrm{Al}_{2} \mathrm{O}_{3}$, which are accompanied by both either increase (in the case of $\delta-\mathrm{Al}_{2} \mathrm{O}_{3}$ increase) and or decrease (in the case of an increase in $\alpha-\mathrm{Al}_{2} \mathrm{O}_{3}$ ) in the volume and occur with different intensities, are probably to be the main cause for the non-monotonic variations in the porosity of plasma-sprayed samples 
during heating. The revealed regularities of heating-induced variations in the porosity of plasma- sprayed products made from the pure aluminum oxide are steadily repeated. This makes it possible to purposefully change the porosity of such products using heat treatments.

\section{CONCLUSIONS}

Polymorphic transformations affect the porosity of plasma-sprayed products fabricated from the pure aluminum oxide. Non-monotononic variations in the porosity of these products during heating is related to the peculiarities of changes in the volume upon polymorphic transformations. The revealed regularities in varitaions of the porosity of plasma-sprayed products fabricated from the pure aluminum oxide make it possible to control the porosity by heat treatments.

\section{REFERENCES}

[1] STEPNOV, A., KUTEPOV, A., BELYAEV, I. and KOLCHUGINA, N. Phase composition and service properties of refractory ceramic mold for single crystal growing. In METAL 2012: 21rd International Conference on Metallurgy and Materials. Ostrava: TANGER, 2012, pp.1-4.

[2] BELYAEV, I.V., STEPNOV, A.A., KIREEV, A.V. and PAVLOV, A.A. Refractory ceramic products from pure oxides with getter coatings. // Refractories and Industrial Ceramics, 2018, vol. 58, Issue 6, pp.615-617.

[3] MATRENIN, S.V. and SLOSMAN, A.I. Engineering Ceramics [in Russia]. Tomsk: Tomsk Politekh. Univ., 2004, p. 241.

[4] BUDNIKOV, P.P and others. New ceramics. Ed. BUDNIKOV, P.P. [in Russian]. Moscow: Stroyizdat, 1969, p. 309.

[5] POLUBOYARINOV, D.N. and others Ceramics of highly refractory oxides. Ed. D.N. POLUBOYARINOV and POPILSKY, R.Ya. [in Russian]. Moscow: Metallurgy, 1977, p. 304.

[6] ZHIJIAN, Yin, SHUNYAN, Tao, XIAMING, Zhou. Effect of the thickness on properties of $\mathrm{Al} 2 \mathrm{O} 3$ coatings deposited by plasma spraying. Materials characterization, 2011, 62, pp.90-93.

[7] HAO, Du, JAE, Heyg Shin and SOO, Wohn Lee. Study on Porosity of Plasma-Sprayed Coatings by Digital Image Analysis Method. Journal of Thermal Spray Technology, 2005, Vol.14(4) December, pp.453-461.

[8] OSKAN, Sarikaya. Effect of some parameters on microstructure and hardness of alumina coatings prepared by the air plasma spraying process. Surface and Coatings Technology, 2005, 190, pp.388-393.

[9] OSKAN, Sarikaya. Effect of the substrate temperature on properties of plasma sprayed $\mathrm{Al} 2 \mathrm{O} 3$ coatings. Materials and Design, 2005, 26, pp.53-57.

[10] KOSENKO, N.F. Alumina polymorphism. Izv. universities. Chemistry and chemical technology, 2011, t.54, issue 5, pp.3-16.

[11] KALININA, A.M. Polymorphic transformations in aluminum oxide. Journal of Inorganic Chemistry, 1959, Vol.4, pp. 1260-1269.

[12] STOROZH, V.V., AKIMOV, P.Ya., GORELIK, I.V. The study of polymorphic transformations in aluminum oxide. Journal of Technical Physics, 1996, v.66, issue 9, pp.86-97.

[13] SAMONOV, G.V. and others. Physical and chemical properties of oxides [in Russian] / Ed. SAMONOV, G.V. Moscow: Metallurgy, 1978. p. 472.

[14] KOVARIK, L., BOWDEN, M., GENC, A., SZANYI, J., PEDEN, C.H.F., KWAK, J.H., Structure of $\delta$ Alumina: Toward the Atomic Level Understanding of Transition Alumina Phases. J. Phys. Chem. C, 2014. vol. 118, pp. 18051-18058. 